\title{
New Fragment Separation Technology for Superheavy Element Research
}

D.A. Shaughnessy, K.J. Moody, R.A. Henderson, J.M. Kenneally, J.H. Landrum, R.W. Lougheed, J.B. Patin, M.A. Stoyer, N.J. Stoyer, J.F. Wild, and P.A. Wilk

February 11, 2008 


\section{Disclaimer}

This document was prepared as an account of work sponsored by an agency of the United States government. Neither the United States government nor Lawrence Livermore National Security, LLC, nor any of their employees makes any warranty, expressed or implied, or assumes any legal liability or responsibility for the accuracy, completeness, or usefulness of any information, apparatus, product, or process disclosed, or represents that its use would not infringe privately owned rights. Reference herein to any specific commercial product, process, or service by trade name, trademark, manufacturer, or otherwise does not necessarily constitute or imply its endorsement, recommendation, or favoring by the United States government or Lawrence Livermore National Security, LLC. The views and opinions of authors expressed herein do not necessarily state or reflect those of the United States government or Lawrence Livermore National Security, LLC, and shall not be used for advertising or product endorsement purposes.

\section{Auspices Statement}

This work performed under the auspices of the U.S. Department of Energy by Lawrence Livermore National Laboratory under Contract DE-AC52-07NA27344. This work was funded by the Laboratory Directed Research and Development Program at LLNL under project tracking code 04-ERD-085. 


\section{FY07 LDRD Final Report New Fragment Separation Technology for Superheavy Element Research LDRD Project Tracking Code: 04-ERD-085 Dawn Shaughnessy, Principal Investigator}

\section{Summary}

This project consisted of three major research areas: 1 ) development of a solid Pu ceramic target for the MASHA separator, 2) chemical separation of nuclear decay products, and 3) production of new isotopes and elements through nuclear reactions. There have been 16 publications as a result of this project, and this collection of papers summarizes our accomplishments in each of the three areas of research listed above.

The MASHA (Mass Analyzer for Super-Heavy Atoms) separator is being constructed at the U400 Cyclotron at the Flerov Laboratory of Nuclear Reactions in Dubna, Russia. The purpose of the separator is to physically separate the products from nuclear reactions based on their isotopic masses rather than their decay characteristics. The separator was designed to have a separation between isotopic masses of \pm 0.25 amu, which would enable the mass of element 114 isotopes to be measured with outstanding resolution, thereby confirming their discovery. In order to increase the production rate of element 114 nuclides produced via the ${ }^{244} \mathrm{Pu}+{ }^{48} \mathrm{Ca}$ reaction, a new target technology was required. Instead of a traditional thin actinide target, the MASHA separator required a thick, ceramic-based Pu target that was thick enough to increase element 114 production while still being porous enough to allow reaction products to migrate out of the target and travel through the separator to the detector array located at the back end.

In collaboration with UNLV, we began work on development of the Pu target for MASHA. Using waste-form synthesis technology, we began by creating zirconiabased matrices that would form a ceramic with plutonium oxide. We used samarium oxide as a surrogate for Pu and created ceramics that had varying amounts of the starting materials in order to establish trends in material density and porosity. The results from this work are described in more detail in Refs. $[1,4,10]$. Unfortunately, work on MASHA was delayed in Russia because it was found that the efficiency of transporting products from the target chamber to the detector array was much too low for applications in heavy element experiments where production rates are on the order of one atom per day or less. Work continues on the MASHA separator, and once the efficiency has been improved, we plan to continue our work on the Pu target for future element 114 experiments.

Due to the delays of the MASHA separator, work on establishing the identity of heavy element species produced through nuclear reactions focused instead on chemical separations. In particular, element 115 decays through a series of alpha decays, terminating with an element 105 isotope with a long half-life ( $\sim 1$ day). By chemically separating the element 105 daughter and observing its subsequent fission decay, the identity of the original parent nucleus can be established through the genetic correlation of the initial series of alpha decays. Chemical separations of element 105 were developed in Switzerland, Russia, and at LLNL. Over the course of two experiments, reaction products from the ${ }^{243} \mathrm{Am}+{ }^{48} \mathrm{Ca}$ reaction were collected in a copper block and subsequently processed for chemical separation of the Group Five elements $[8,9,13,15]$. The Group Five elements were initially separated from the 
Group Four species, and then the samples were sub-divided into tantalum and niobium fractions. All of the fission events were observed in the tantalum fractions, which implied that element 105 behaved more like tantalum under the chemical conditions of these experiments. These experiments were very successful, and not only demonstrated that chemical separation could be performed on single atoms of interest, but also lent proof to the identity of the parent nucleus as element 115 . Subsequent analysis of the alpha spectra taken during the experiment further prove that the fission events observed during the two experiments came from element 105 as the decay daughter of element 115 and could not attributed to interference from other background species [16].

The final aspect of this project was the production of new isotopes and elements. All of the experiments were performed in Dubna at the U400 Cyclotron and the results are described in more detail in Refs. $[2,3,5-8,11,12,14]$. The first experiments were designed to establish the decay properties of isotopes of elements 112,114 , and 116 [5]. Because these isotopic signatures were established through these initial experiments, the discovery of element 118 [11] was possible, since the 118 nuclides decayed into these previously studied isotopes. This was the first successful report of the discovery of element 118 , which was reported by the media to a large extent. The last experiment that was performed for this project was the production and detection of a new isotope of element 113 [14].

\section{References in chronological order:}

1. "Development of a Plutonium Ceramic Target for the MASHA Separator", D.A. Shaughnessy, K.J. Moody, J.M. Kenneally, J.F. Wild, M.A. Stoyer, R.W. Lougheed, A.V. Yeremin, and Yu.Ts. Oganessian, Nucl. Phys. A 734, E5, 2004, LLNL-JRNL400219 (published conference proceeding.)

2. "Heavy Element Research at Dubna", Yu.Ts. Oganessian, V.K. Utyonkov, Yu.V. Lobanov, F.Sh. Abdullin, A.N. Polyakov, I.V. Shirokovsky, Yu.S. Tsyganov, G.G. Gulbekian, S.L. Bogomolov, B.N. Gikal, A.N. Mezentsev, S. Iliev, V.G. Subbotin, A.M. Sukhov, A.A. Voinov, G.V. Buklanov, K. Subotic, V.I. Zagrebaev, M.G. Itkis, J.B. Patin, K.J. Moody, J.F. Wild, M.A. Stoyer, N.J. Stoyer, D.A. Shaughnessy, J.M. Kenneally, and R.W. Lougheed, Nucl. Phys. A 734, 109, 2004, LLNL-PROC-400264 (published conference proceeding.)

3. "Superheavy Element Isotopes, Decay Properties", K.J. Moody, Nucl. Phys. A 734, 188, 2004, UCRL-JRNL-202241 (published conference proceeding.)

4. "A Plutonium Ceramic Target for MASHA", P.A. Wilk, D.A. Shaughnessy, K.J. Moody, J.M. Kenneally, J.F. Wild, M.A. Stoyer, J.B. Patin, R.W. Lougheed, B.B. Ebbinghaus, R.L. Landingham, Yu.Ts. Oganessian, A.V. Yeremin, and S.N. Dmitriev, Proceedings of the International Symposium on Exotic Nuclei, EXON04, Peterhof, Russia, July 5-12, 2004, World Scientific Publishing, 2004, UCRL-PROC-205183 (published conference proceeding.)

5. "Measurements of Cross Sections and Decay Properties of the Isotopes of Elements 112, 114, and 116 Produced in the Fusion Reactions ${ }^{233,238} \mathrm{U}$, ${ }^{242} \mathrm{Pu}$, and ${ }^{248} \mathrm{Cm}+{ }^{48} \mathrm{Ca}$ ", Yu.Ts. Oganessian, V.K. Utyonkov, Yu.V. Lobanov, F.Sh. Abdullin, A.N. Polyakov, I.V. Shirokovsky, Yu.S. Tsyganov, G.G. Gulbekian, S.L. Bogomolov, B.N. Gikal, A.N. Mezentsev, S. Iliev, V.G. Subbotin, A.M. Sukhov, A.A. Voinov, G.V. Buklanov, K. Subotic, V.I. Zagrebaev, M.G. Itkis, J.B. Patin, K.J. Moody, J.F. Wild, 
M.A. Stoyer, N.J. Stoyer, D.A. Shaughnessy, J.M. Kenneally, P.A. Wilk, and R.W. Lougheed, Phys. Rev. C 70, 064609, 2004, UCRL-JRNL-206491 (refereed publication.)

6. "New Elements from Dubna", Yu.Ts. Oganessian, V.K. Utyonkov, Yu.V. Lobanov, F.Sh. Abdullin, A.N. Polyakov, I.V. Shirokovsky, Yu.S. Tsyganov, G.G. Gulbekian, S.L. Bogomolov, B.N. Gikal, A.N. Mezentsev, S. Iliev, V.G. Subbotin, A.M. Sukhov, A.A. Voinov, G.V. Buklanov, K. Subotic, V.I. Zagrebaev, M.G. Itkis, J.B. Patin, K.J. Moody, J.F. Wild, M.A. Stoyer, N.J. Stoyer, D.A. Shaughnessy, J.M. Kenneally, and R.W. Lougheed, Eur. Phys. J. A 25, Suppl. 1, 589, 2005, LLNL-PROC-400265 (published conference proceeding.)

7. "Random Probability Analysis of Recent ${ }^{48}$ Ca Experiments", M.A. Stoyer, J.B Patin, J.M. Kenneally, K.J. Moody, D.A. Shaughnessy, N.J. Stoyer, J.F. Wild, P.A. Wilk, V.K. Utyonkov, and Yu.Ts. Oganessian", Eur. Phys. J. A 25, Suppl. 1, 595, 2005, UCRLPROC-206941 (published conference proceeding.)

8. "Synthesis of Elements 115 and 113 in the Reaction ${ }^{243} \mathrm{Am}+{ }^{48} \mathrm{Ca}$ ", Yu.Ts. Oganessian, V.K. Utyonkov, S.N. Dmitriev, Yu.V. Lobanov, M.G. Itkis, A.N. Polyakov, Yu.S. Tsyganov, A.N. Mezentsev, A.V. Yeremin, A.A. Voinov, E.A. Sokol, G.G. Gulbekian, S.L. Bogomolov, S. Iliev, V.G. Subbotin, A.M. Sukhov, G.V. Buklanov, S.V. Shishkin, V.I. Chepygin, G.K. Vostokin, N.V. Aksenov, M. Hussonnois, K. Subotic, V.I. Zagrebaev, K.J. Moody, J.B. Patin, J.F. Wild, M.A. Stoyer, N.J. Stoyer, D.A. Shaughnessy, J.M. Kenneally, P.A. Wilk, R.W. Lougheed, H.W. Gäggeler, D. Schumann, H. Bruchertseifer, and R. Eichler, Phys. Rev. C 72, 034611, 2005, UCRLJRNL-210965 (refereed publication.)

9. "Chemical Identification of Dubnium as a Decay Product of Element 115 Produced in the Reaction ${ }^{48} \mathrm{Ca}+{ }^{243} \mathrm{Am}$ ", S.N. Dmitriev, Yu.Ts. Oganessian, V.K. Utyonkov, S.V. Shishkin, A.V. Yeremin, Yu.V. Lobanov, Yu.S. Tsyganov, V.I. Chepygin, E.A. Sokol, G.K. Vostokin, N.V. Aksenov, M. Hussonnois, M.G. Itkis, H.W. Gäggeler, D. Schumann, H. Bruchertseifer, R. Eichler, D.A. Shaughnessy, P.A. Wilk, J.M. Kenneally, M.A. Stoyer, and J.F Wild, Mendeleev Commun. 15, 1, 2005, UCRL-JRNL215890 (refereed publication.)

10. "Ceramic Plutonium Target Development for the MASHA Separator for the Synthesis of Element 114", D.A. Shaughnessy, P.A. Wilk, K.J. Moody, J.M. Kenneally, J.F. Wild, M.A. Stoyer, N.J. Stoyer, J.B. Patin, J.H. Landrum, R.W. Lougheed, Yu.Ts. Oganessian, A.V. Yeremin, S.N. Dmitriev, T. Hartmann, and K.R. Czerwinski, Proccedings of the $8^{\text {th }}$ Actinide Conference, Actinides 2005, Manchester, UK, July 4-8, 2005, RSC Publishing, 2006, UCRL-PROC-213358 (published conference proceeding.)

11. "Synthesis of the Isotopes of Elements 118 and 116 in the ${ }^{249} \mathrm{Cf}$ and ${ }^{245} \mathrm{Cm}+{ }^{48} \mathrm{Ca}$ Fusion Reaction", Yu.Ts. Oganessian, V.K. Utyonkov, Yu.V. Lobanov, F.Sh. Abdullin, A.N. Polyakov, R.N. Sagaidak, I.V. Shirokovsky, Yu.S. Tsyganov, A.A. Voinov, G.G. Gulbekian, S.L. Bogomolov, B.N. Gikal, A.N. Mezentsev, S. Iliev, V.G. Subbotin, A.M. Sukhov, K. Subotic, V.I. Zagrebaev, G.K. Vostokin, M.G. Itkis, K.J. Moody, J.B. Patin, D.A. Shaughnessy, M.A. Stoyer, N.J. Stoyer, P.A. Wilk, J.M. Kenneally, J.H. Landrum, J.F. Wild, and R.W. Lougheed, Phys. Rev. C 74, 044602, 2006, UCRL-JRNL-220958 (refereed publication.) 
12. "Island Ahoy!", M.A. Stoyer, Nature 442, 876, 2006, UCRL-JRNL-224404 (editorial in refereed publication.)

13. "Chemical Identification of a Long-Lived Isotope of Dubnium, a Descendant of Element 115", N.J. Stoyer, J.H. Landrum, P.A. Wilk, K.J. Moody, J.M. Kenneally, D.A. Shaughnessy, M.A. Stoyer, J.F. Wild, R.W. Lougheed, S.N. Dmitriev, Yu.Ts.

Oganessian, S.V. Shishkin, N.V. Aksenov, E.E. Tereshatov, G.A. Bozhikov, G.K. Vostokin, V.K. Utyonkov, and A.V. Yeremin, Nucl. Phys. A 787, 388C, 2007, UCRLPROC-224777 (published conference proceeding.)

14. "Synthesis of the Isotope ${ }^{282} 113$ in the ${ }^{237} \mathrm{~Np}+{ }^{48} \mathrm{Ca}$ Fusion Reaction", Yu.Ts. Oganessian, V.K. Utyonkov, Yu.V. Lobanov, F.Sh. Abdullin, A.N. Polyakov, R.N. Sagaidak, I.V. Shirokovsky, Yu.S. Tsyganov, A.A. Voinov, G.G. Gulbekian, S.L. Bogomolov, B.N. Gikal, A.N. Mezentsev, V.G. Subbotin, A.M. Sukhov, K. Subotic, V.I. Zagrebaev, G.K. Vostokin, M.G. Itkis, R.A. Henderson, J.M. Kenneally, J.H. Landrum, K.J. Moody, D.A. Shaughnessy, M.A. Stoyer, N.J. Stoyer, and P.A. Wilk, Phys. Rec. C 76, 011601, 2007, UCRL-JRNL-230346 (refereed publication.)

15. "Separation of Group Five Elements by Reversed-Phase Chromatography", P.A. Wilk, J.H. Landrum, D.A. Shaughnessy, J.M. Kenneally, N.J. Stoyer, M.A. Stoyer, K.J. Moody, N.V. Aksenov, G.A. Bozhikov, E.E. Tereshatov, G.K. Vostokin, S.V. Shishkin, and S.N. Dmitriev, J. Radioanal. Nucl. Chem. 275, 651657, 2008, UCRL-JRNL228727 (refereed publication.)

16. " ${ }^{243} \mathrm{Am}+{ }^{48} \mathrm{Ca}$ : A Second Look at the Rf/Db Data Set", R.A. Henderson and K.J. Moody, LLNL internal report, 2008, LLNL-TR-400981-DRAFT (in preparation.) 